DIGITALCOMMONS

- @WAYNESTATE-
Journal of Modern Applied Statistical Methods

Volume 6 | Issue 2

Article 9

$11-1-2007$

\title{
The Effect Of Different Degrees Of Freedom Of The Chi-square Distribution On The Statistical Power Of'The t, Permutation t, And Wilcoxon Tests
}

Michèle Weber

San Jose, California

Follow this and additional works at: http://digitalcommons.wayne.edu/jmasm

Part of the Applied Statistics Commons, Social and Behavioral Sciences Commons, and the Statistical Theory Commons

\section{Recommended Citation}

Weber, Michèle (2007) "The Effect Of Different Degrees Of Freedom Of The Chi-square Distribution On The Statistical Power Of

The t, Permutation t, And Wilcoxon Tests," Journal of Modern Applied Statistical Methods: Vol. 6 : Iss. 2 , Article 9.

DOI: $10.22237 /$ jmasm/1193890080

Available at: http://digitalcommons.wayne.edu/jmasm/vol6/iss2/9

This Regular Article is brought to you for free and open access by the Open Access Journals at DigitalCommons@WayneState. It has been accepted for inclusion in Journal of Modern Applied Statistical Methods by an authorized editor of DigitalCommons@WayneState. 
The Effect Of Different Degrees Of Freedom Of The Chi-square Distribution

On The Statistical Power Of The t, Permutation t, And Wilcoxon Tests

\author{
Michèle Weber \\ San Jose, California
}

The Chi-square distribution is used quite often in Monte Carlo studies to examine statistical power of competing statistics. The power spectrum of the t-test, Wilcoxon test, and permutation $t$ test are compared under various degrees of freedom for this distribution. The two t tests have similar power, which is generally less than the Wilcoxon.

Key words: t-test, Wilcoxon test, permutation test, Chi Square, Monte Carlo simulation

\section{Introduction}

Weber (2006) found that the power of the Wilcoxon test was only somewhat higher than that of the $t$ and permutation t-tests in the Chisquare distribution with 6 degree of freedom. It was expected that the Wilcoxon test is much more powerful than the t-test under nonnormality (Blair \& Higgins, 1985; Hodges \& Lehmann, 1956; Sawilowsky, 1990; Sawilowsky \& Fahoome, 2003).

\section{Purpose}

This study investigates the effect on statistical power of the $t$, permutation $t$ and Wilcoxon tests when data are sampled from the Chi squared distribution.

\section{Methodology}

A Monte Carlo simulation was used to study the properties of the two independent samples Student's $\mathrm{t}$ test, the permutation $\mathrm{t}$ test, and the Wilcoxon Rank Sum test with regard to their statistical power.

Michèle Weber, PhD, LMSW, LMFT, is an independent researcher, who resides in San Jose, California. Her areas of interest are in Monte Carlo methods and hypothesis tests. Email her at M.Fatal-Weber@worldnet.att.net
Nominal alpha was selected at $\alpha=0.05$. The samples were composed of random numbers obtained from Rangen 2.0, which is a collection of subroutines to generate pseudo-random numbers (Sawilowsky \& Fahoome, 2003). Small sample sizes used for this study were $\mathrm{n}_{1}=$ $\mathrm{n}_{2}=10$ and $\mathrm{n}_{1}=5$ and $\mathrm{n}_{2}=15$. The larger sample sizes were $n_{1}=n_{2}=20$ and $n_{1}=10$ and $\mathrm{n}_{2}=30$. One thousand five hundred repetitions were done to obtain the power, with shifts in means of $\mu=.2 \sigma, .5 \sigma, .8 \sigma$ and $1.2 \sigma$.

The procedures were performed on the Chi-square distribution with degree of freedom $1,2,3,4,5,6,8,10,20$ and 40.

\section{Results}

Comparison of Power between $t$ and Permutation $t$ tests

All results are presented in the Appendix. For the even sample sizes, $\mathrm{n}_{1}=\mathrm{n}_{2}=$ 10 and $\mathrm{n}_{1}=\mathrm{n}_{2}=20$, the $\mathrm{t}$ and permutation $\mathrm{t}$-tests reflected the same power regardless of the degree of freedom of the Chi-square distribution. Indeed, as shown in the different graphs, the power starts somewhat low at .10 for small sample sizes and .15 for $\mathrm{n}_{1}=\mathrm{n}_{2}=20$ when the shift $\mu$ is $.2 \sigma$. As the shifts in means increase, the power increases to an average of .97 for $\mathrm{n}_{1}=\mathrm{n}_{2}$ $=10$ and .93 for larger sample sizes when $\mu=$ $1.2 \sigma$.

For uneven sample sizes, the t-test is less powerful than that of the permutation t-test. As the shift in means increases, the difference between the power of these two tests decreases. 
For $\mathrm{n}_{1}=5$ and $\mathrm{n}_{2}=15$, the difference is .10 at $\mu$ $=.2 \sigma$ and becomes .01 when $\mu=1.2 \sigma$. The disparity is less noticeable for the larger uneven sample sizes, from .06 to .01 with the increase in the shift.

Comparison of Wilcoxon Test with $t$ and Permutation t-tests

For the Chi-square distribution with degree of freedom 1 , the power of the Wilcoxon test starts off somewhat higher than the $t$ and permutation t-tests at .25 for $\mathrm{n}_{1}=\mathrm{n}_{2}=10$. For $\mathrm{n}_{1}$ $=\mathrm{n}_{2}=20$, the power of the Wilcoxon test is .45 and .4 for the larger uneven sample size when $\mu$ $=.2 \sigma$. However, as the shift in means increases, the difference in power between the Wilcoxon and the $t$ and permutation t-tests becomes smaller, until it reaches a plateau.

As the degree of freedom becomes larger, the power difference between the Wilcoxon and the $\mathrm{t}$ and permutation t-tests decreases. When $\mathrm{df}=8$, the power of the three tests is so similar that the graphs do not reflect a difference between them, especially for the other sample sizes. When the degree of freedom is 10 , the Wilcoxon test becomes less powerful than the two t-tests. For $n_{1}=n_{2}=20$, the power of the Wilcoxon test is below the power of the two tests at $\mathrm{df}=40$.

\section{Discussion}

The Chi-square distribution with 1 degree of freedom is extremely asymmetric. Thus, it was expected and found that the Wilcoxon test is, indeed, much more powerful than the $t$ and permutation t-test, as supported by Sawilowsky and Blair (1992).

As the degree of freedom increases, the Chi-square becomes less asymmetric and light tailed. Thus, the power properties of the Student's $t$ and the permutation t-tests were expected to be rehabilitated as the distribution become more normal like, which was confirmed by the results. Indeed, with degrees of freedom 4, 5, 6 and 8, the increased symmetry and decreased tail weights made the permutation ttest and the Student's t-test more competitive, although still decreasingly less powerful than the Wilcoxon Rank-Sum test.

For $\mathrm{df}=20$ and 40 , the $\mathrm{t}$ and permutation t-tests only had a modest power increase over the Wilcoxon test as predicted by the Asymptotic Relative Efficiencies (ARE).

As stated previously, the uneven sample sizes $\left(\mathrm{n}_{1}=5\right.$ and $\mathrm{n}_{2}=15, \mathrm{n}_{1}=10$ and $\left.\mathrm{n}_{2}=30\right)$ offered a different outcome in the smaller degree of freedom of the Chi-square distribution. The difference in power between the Student's t-test and its permutation counterpart can be explained by the fact that the t-test performs worse than the permutation t-test under non-normality and unevenness of the sample size (Sawilowksy \& Fahoome, 2003). As for the superiority of the Wilcoxon test, the results are similar to the Sawilowsky and Blair (1992)'s study.

The power of the Wilcoxon test is superior compared with both the $t$ and permutation t-tests for the Chi-square distribution, though decreasing progressively as the degree of freedom increases from 1 to approximately 10 . Then, the $t$ and permutation $t-$ tests regain their superiority as the distribution with higher degree of freedom becomes more symmetric with lighter tails simulating the normal distribution. Therefore in situations where the data suggest a Chi-square distribution with lower (less than 10) degree of freedom, the Wilcoxon test is preferable to its competitors when the nature of the treatment changes the mean of two independent samples.

\section{References}

Blair, R. C. \& Higgins, J.J. (1985). Comparison of the power of the paired samples $t$ test to that of Wilcoxon's sign-ranks test under various population shapes. Psychological Bulletin, 97, 119-128.

Bukszar, J. \& van den Oord, E. J. (2006). Accurate and efficient power calculations for $2 \times \mathrm{m}$ tables in unmatched casecontrol designs. Statistics in Medicine, 25 (15), 2632.

Gimenez, P.; Bolfarine, H. \& Colosimo, E. A. (2000). Hypotheses testing for error-invariables models. Annals of The Institute of Statistical Mathematics (Tokyo), 52 (4), 698711. 
Hodges, J. \& Lehmann, E. L. (1956). The efficiency of some nonparametric competitors of the $t$ test. Annals of Mathematical Statistics, 27, 324-335.

Shinozabi, O. Y. (2006). Estimation of error variance in ANOVA model and order restricted scale parameters. Annals of The Institute of Statistical Mathematics (Tokyo), 34 (4), 739.

Sawilowsky, S. S. (1990). Nonparametric tests of interaction in experimental design. Review of Educational Research, 60 (1), 91-126.
Sawilowsky, S.S. \& Blair, R.C. (1992). A more realistic look at the robustness and type II error properties of the $t$ test to departures from population normality. Psychological Bulletin, 111, 353-360.

Sawilowsky, S. S. \& Fahoome, G. F. (2003). Statistics Through Monte Carlo Simulation With Fortran. Oak Park, MI: JMASM, Inc.

Weber, M. (2006). Robustness and Power of the $t$, Permutation $t$ and Wilcoxon Tests (Doctoral dissertation, Wayne State University, 2006). 


\section{APPENDIX}

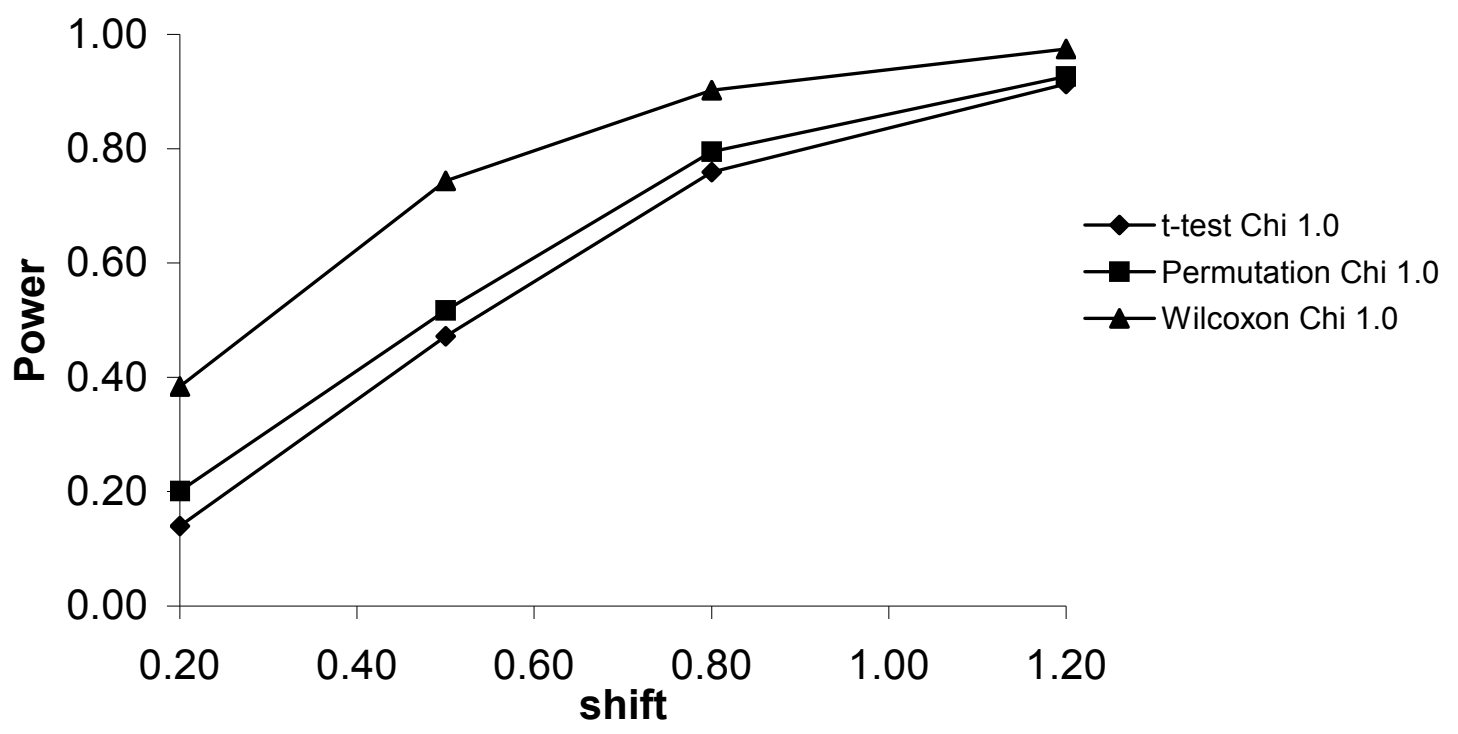

Figure 21. Shift vs. Power in the Chi-Square Distribution $(d f=1)$ for Sample Size $\mathrm{n}_{1}=10, \mathrm{n}_{2}=30$

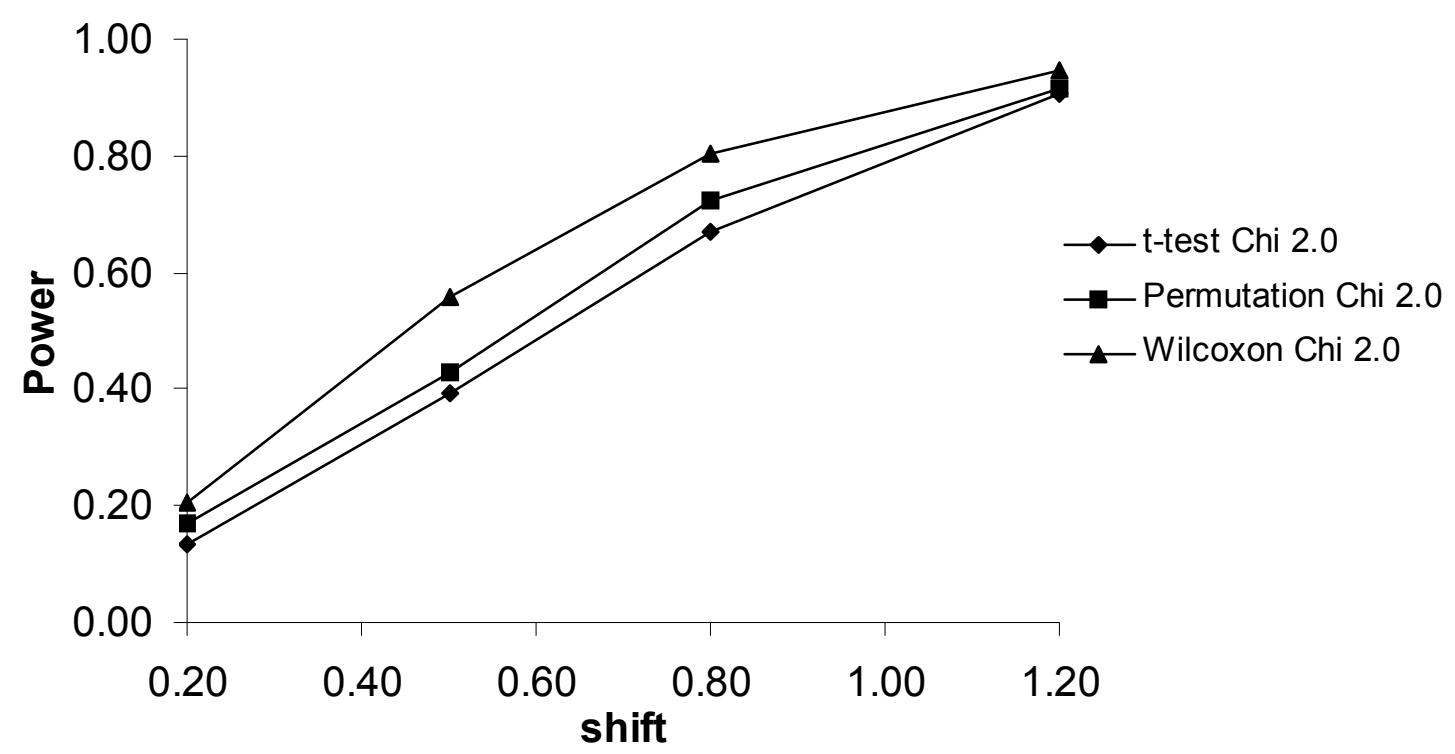

Figure 22. Shift vs. Power in the Chi-Square Distribution ( $d f=2)$ for Sample Size $n_{1}=10, n_{2}=30$ 




Figure 23. Shift vs. Power in the Chi-Square Distribution $(\mathrm{df}=3)$ for Sample Size

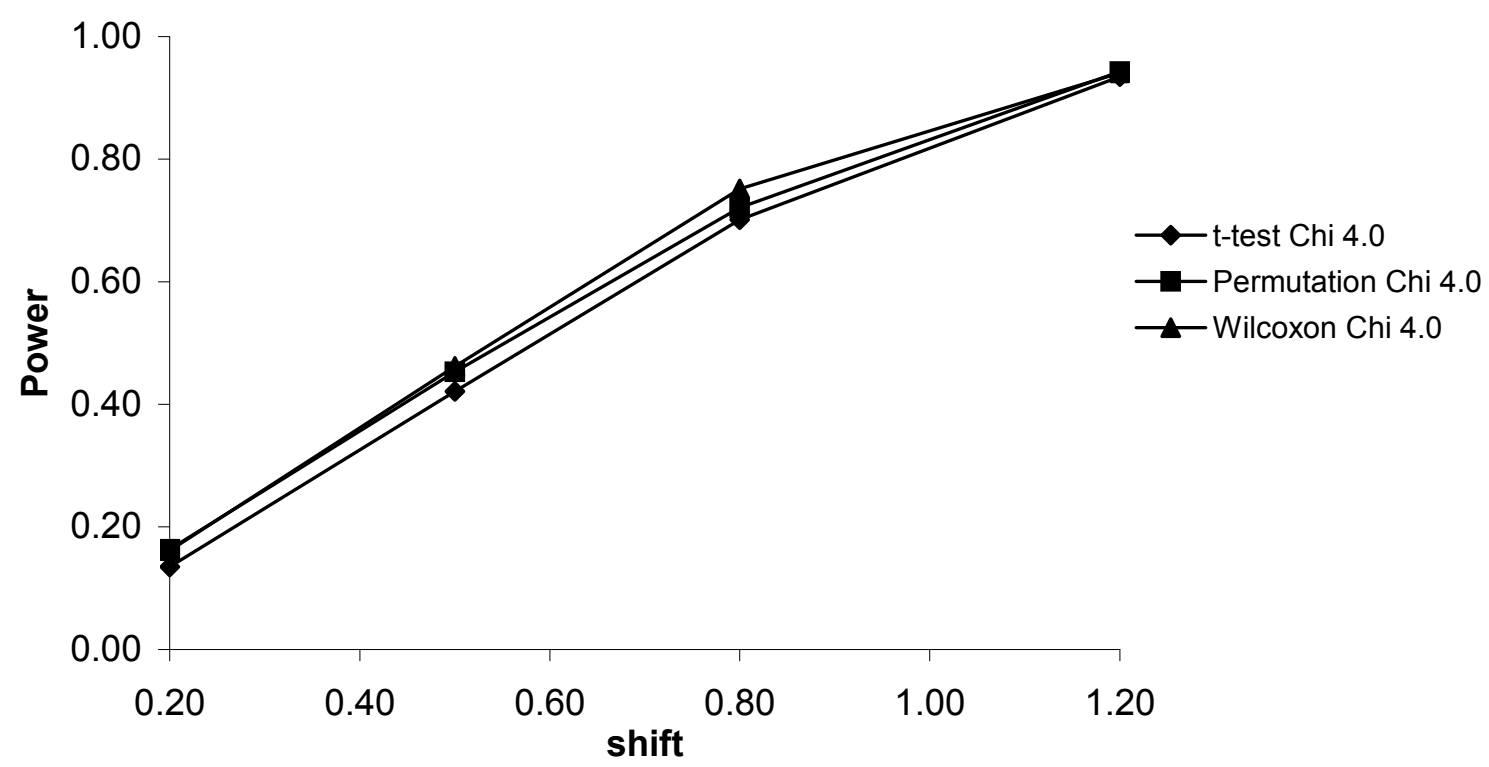

Figure 24. Shift vs. Power in the Chi-Square Distribution $(d f=4)$ for Sample Size $n_{1}=10, n_{2}=30$ 




Figure 25: Shift vs. Power in the Chi-Square Distribution $(d f=5)$ for Sample Size $n_{1}=10, n_{2}=30$

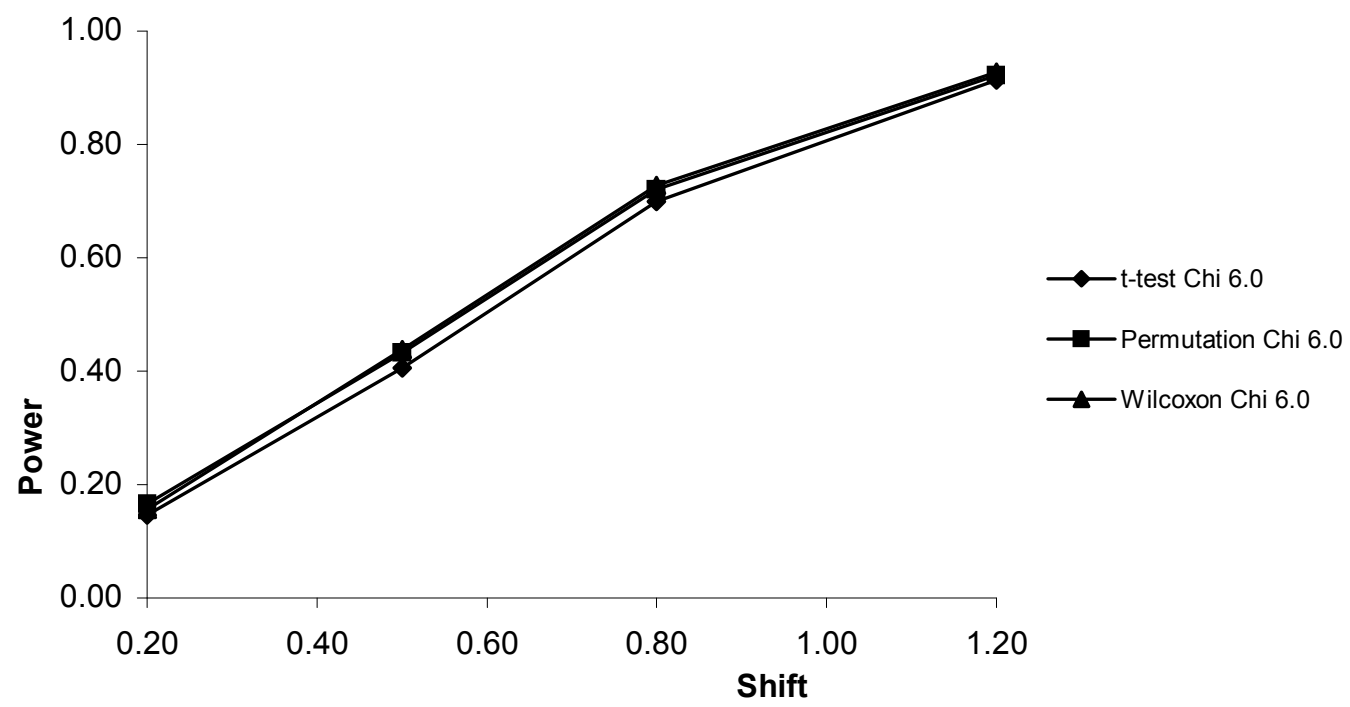

Figure 26: Shift vs. Power in the Chi-Square Distribution $(d f=6)$ for Sample Size $n_{1}=10, n_{2}=30$ 


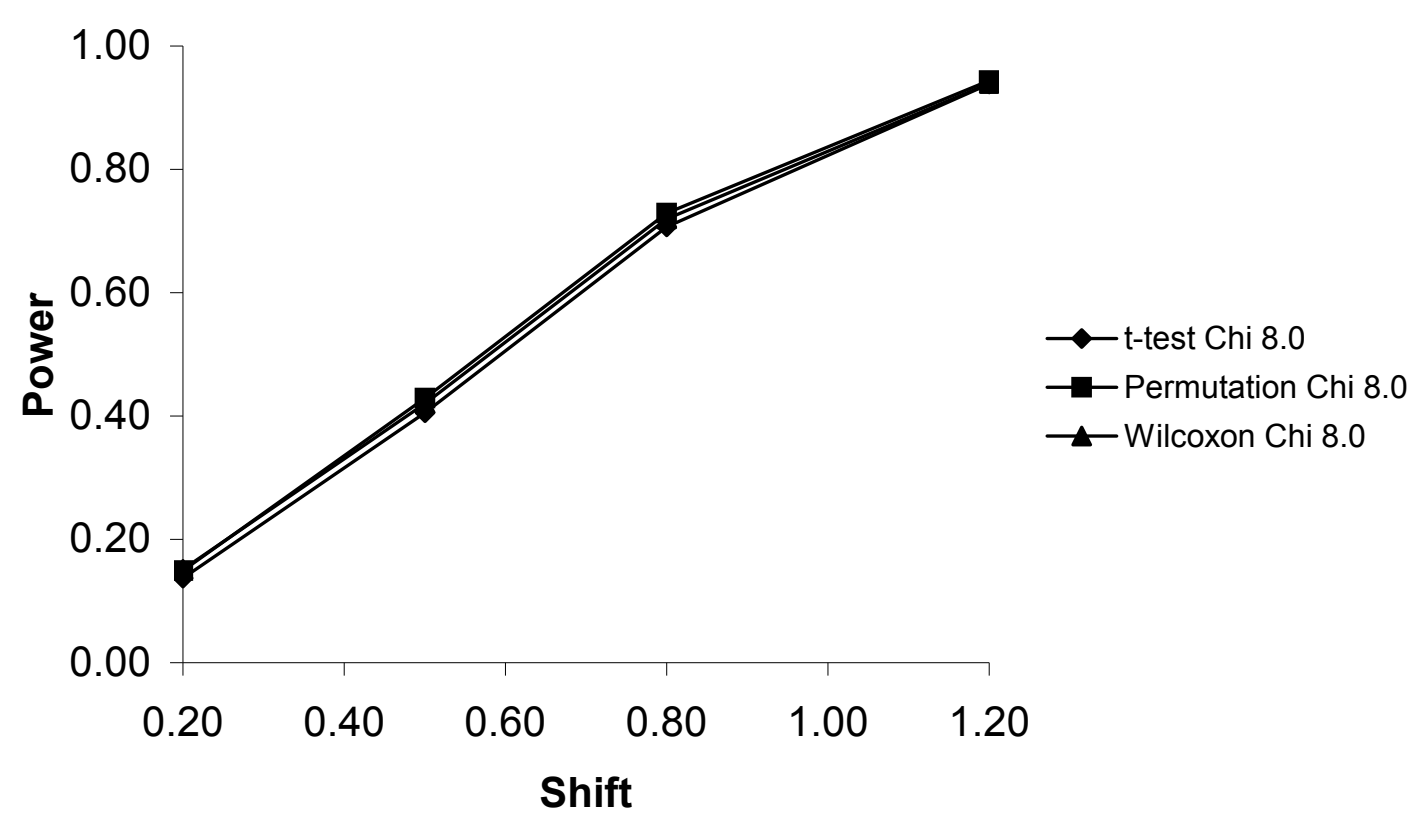

Figure 27: Shift vs. Power in the Chi-Square Distribution $(d f=8)$ for Sample Size $n_{1}=10, n_{2}=30$

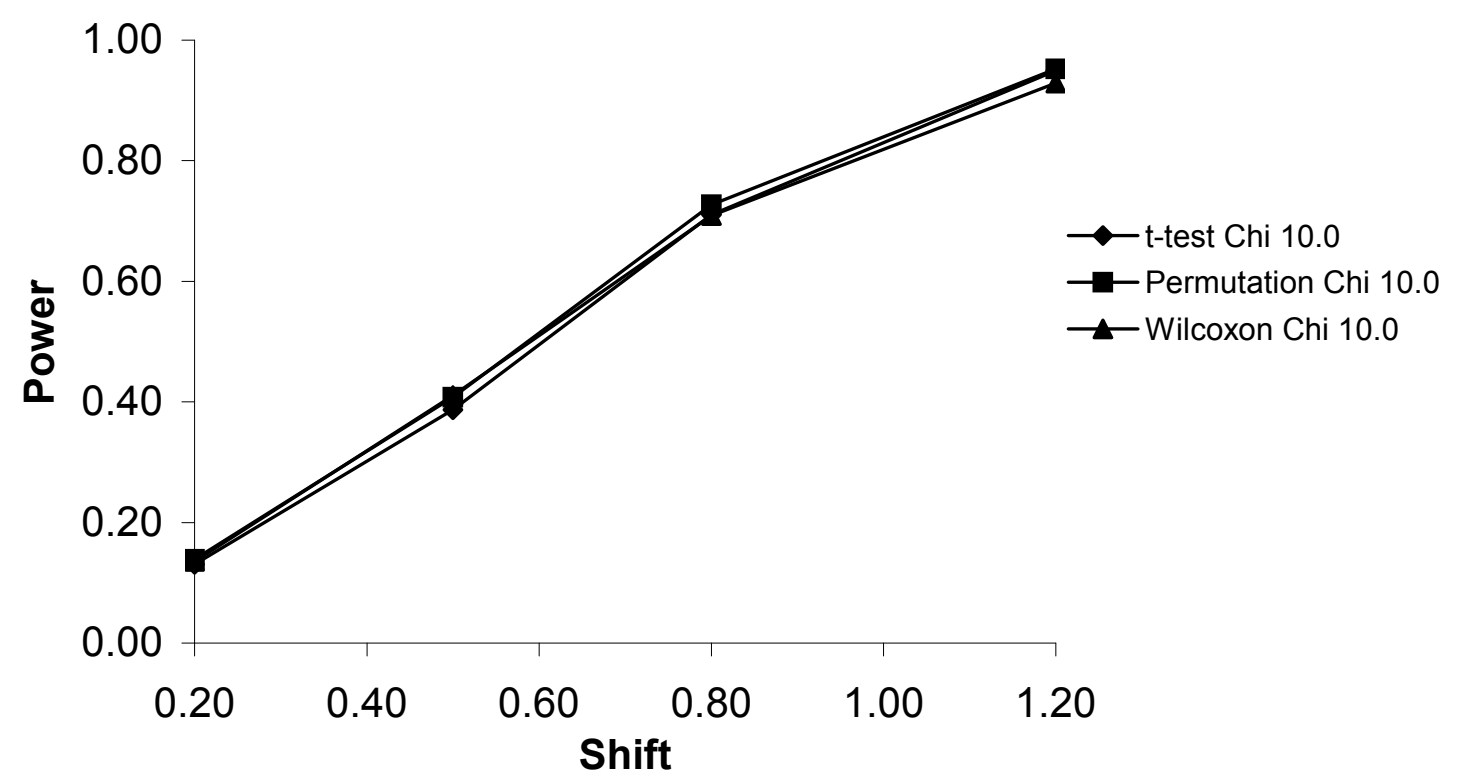

Figure 28: Shift vs. Power in the Chi-Square Distribution ( $d f=10)$ for Sample Size $n_{1}=10, n_{2}=30$ 


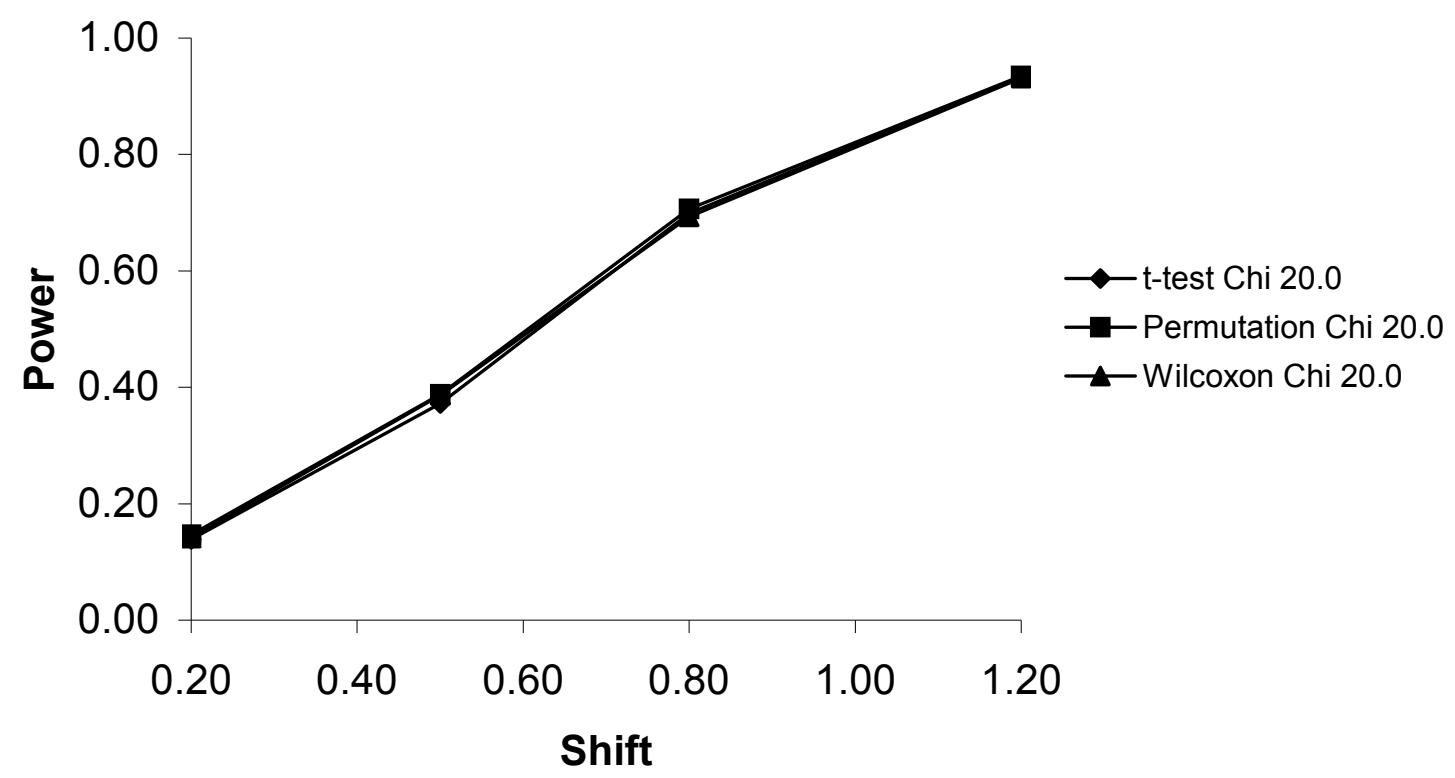

Figure 29: Shift vs. Power in the Chi-Square Distribution $(d f=20)$ for Sample Size $n_{1}=10, n_{2}=30$

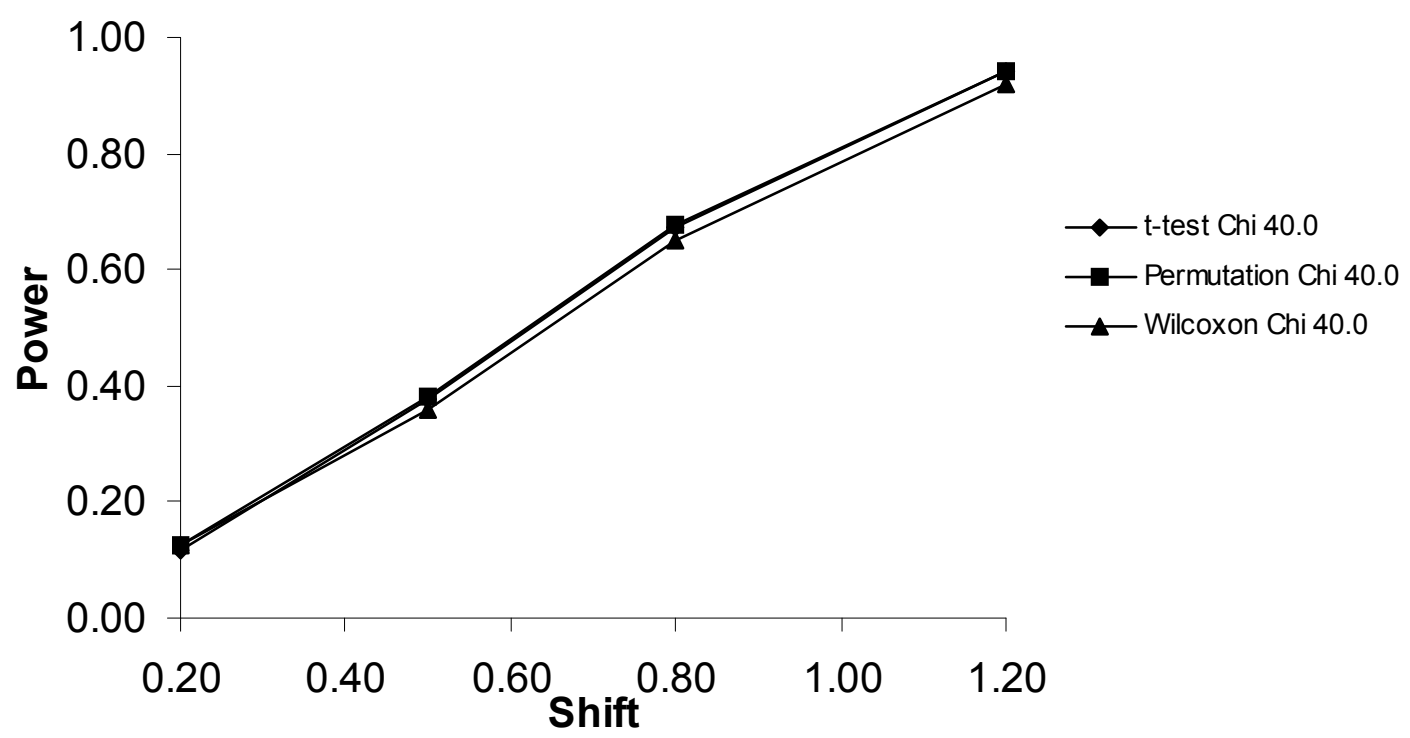

Figure 30: Shift vs. Power in the Chi-Square Distribution $(d f=40)$ for Sample Size $n_{1}=10, n_{2}=30$ 


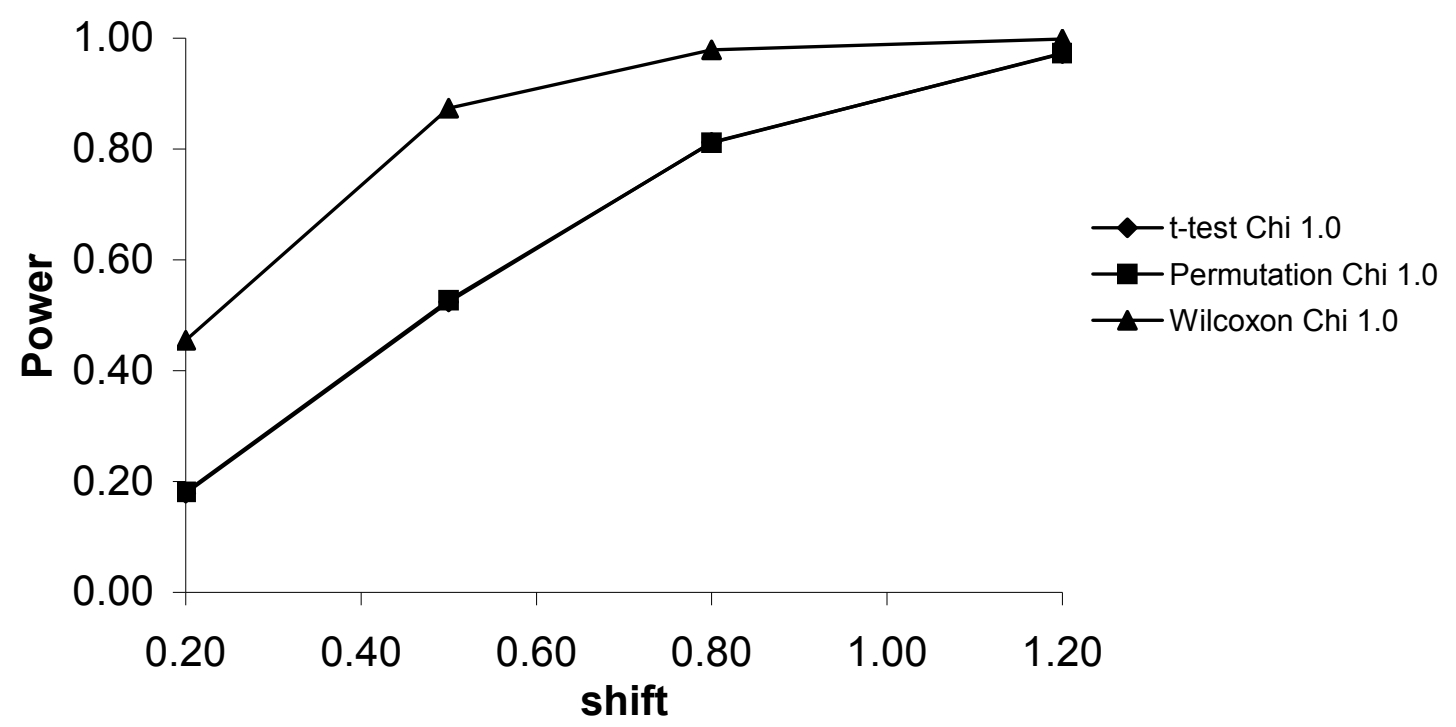

Figure 31: Shift vs. Power in the Chi-Square Distribution $(d f=1)$ for Sample Size $n_{1}=n_{2}=20$

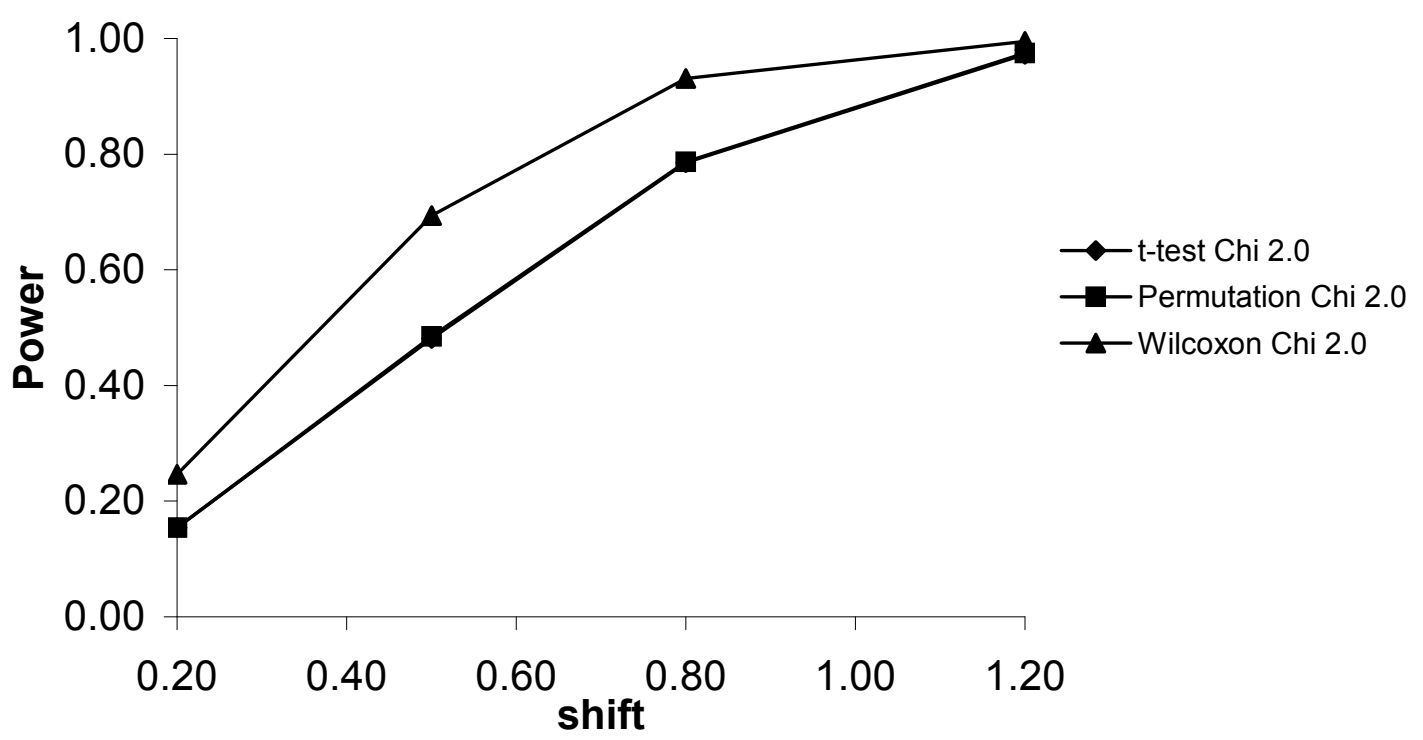

Figure 32: Shift vs. Power in the Chi-Square Distribution $(d f=2)$ for Sample Size $n_{1}=n_{2}=20$ 


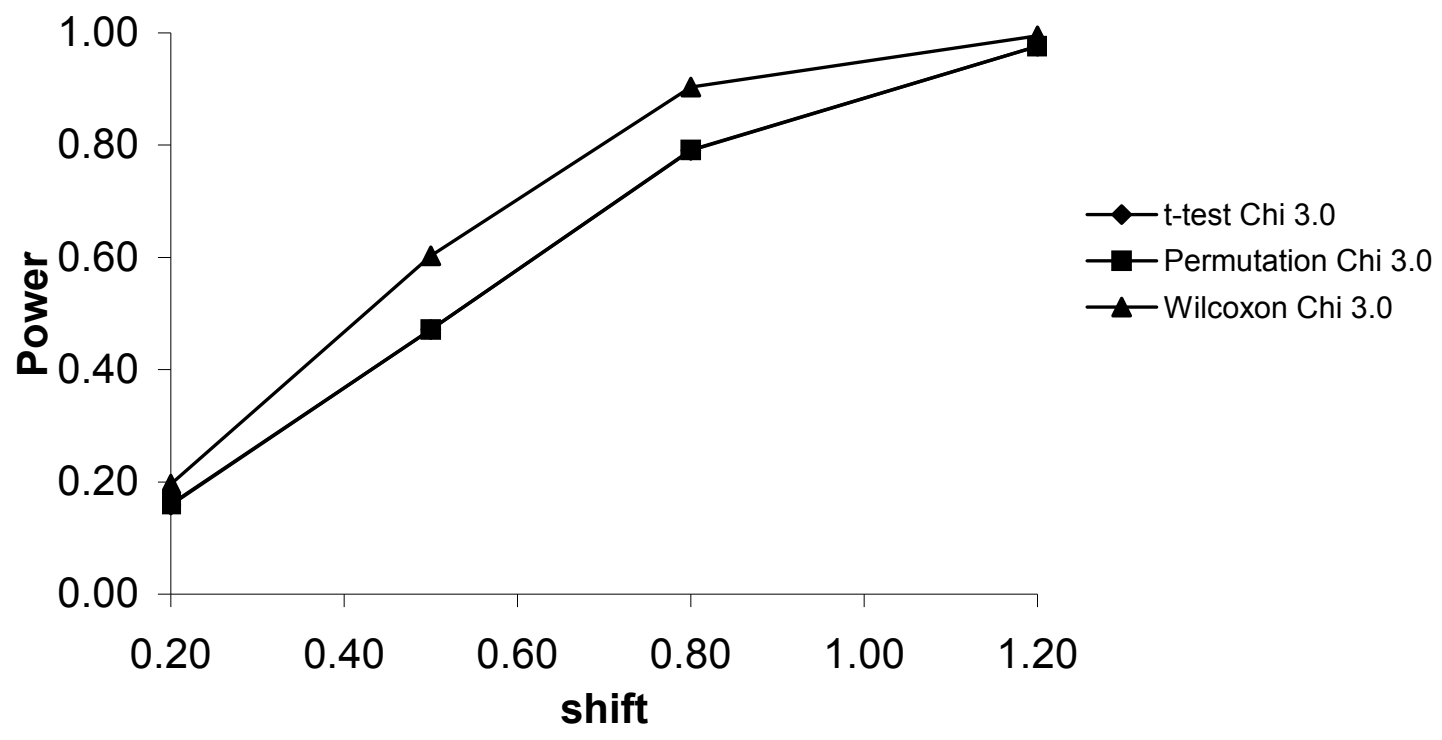

Figure 33: Shift vs. Power in the Chi-Square Distribution $(d f=3)$ for Sample Size $n_{1}=n_{2}=20$

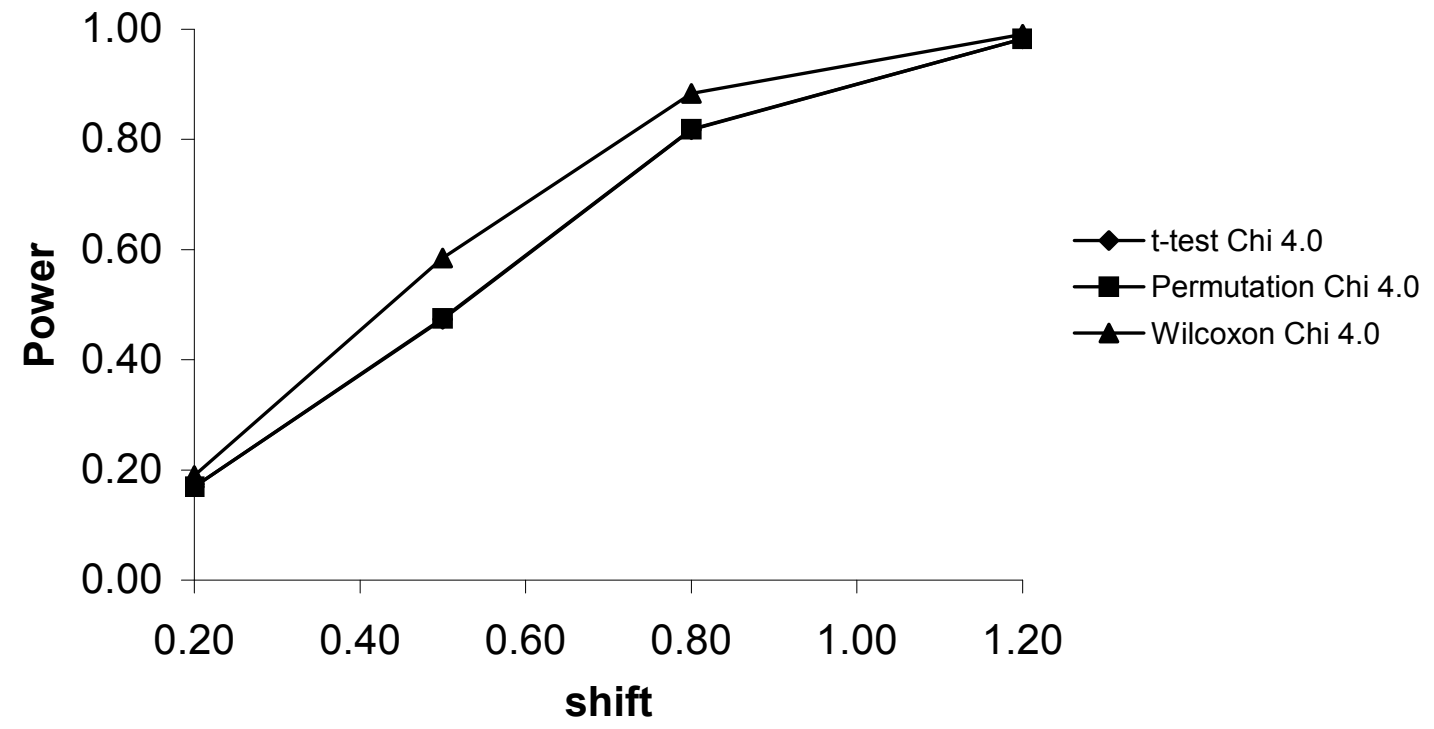

Figure 34: Shift vs. Power in the Chi-Square Distribution $(d f=4)$ for Sample Size $n_{1}=n_{2}=20$ 


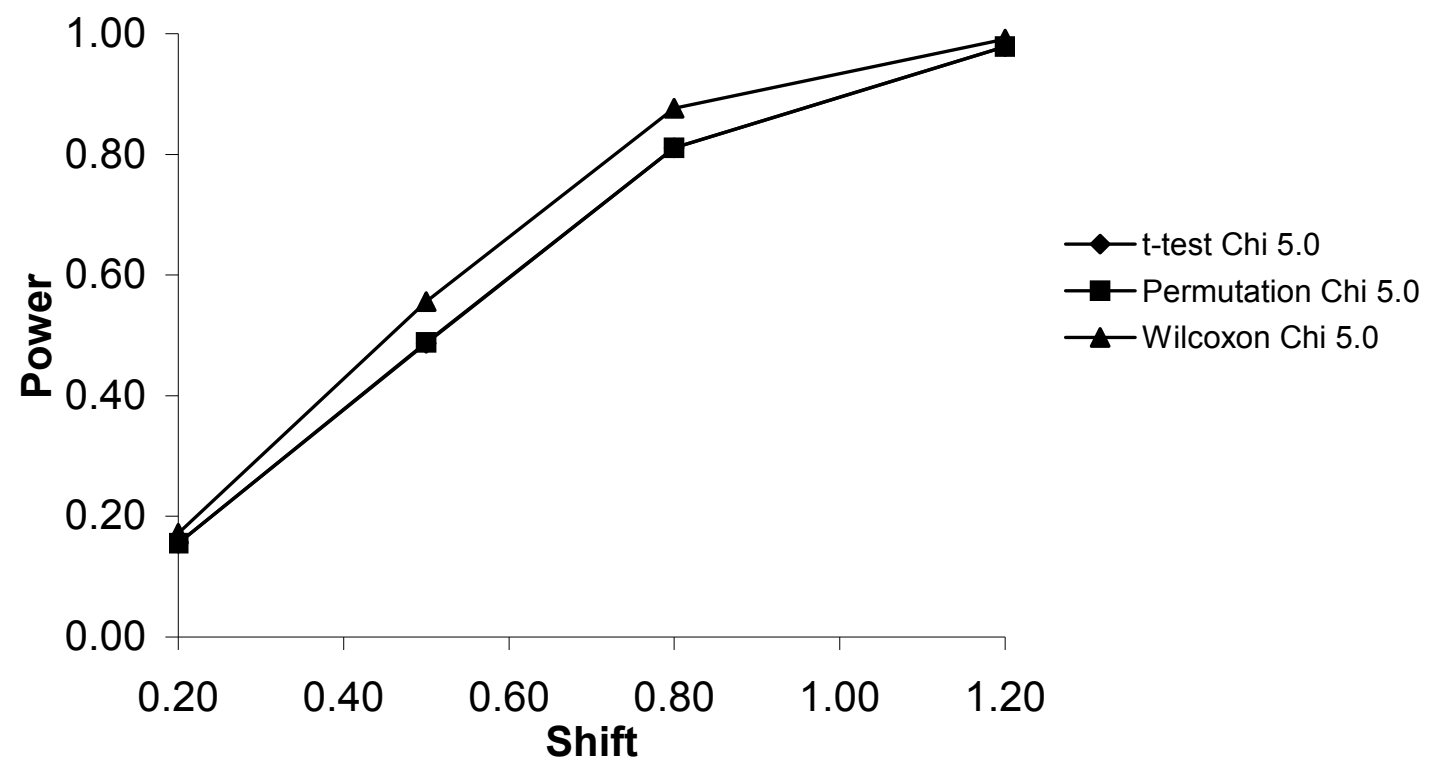

Figure 35: Shift vs. Power in the Chi-Square Distribution ( $d f=5)$ for Sample Size $n_{1}=n_{2}=20$



Figure 36: Shift vs. Power in the Chi-Square Distribution $(d f=6)$ for Sample Size $n_{1}=n_{2}=20$ 


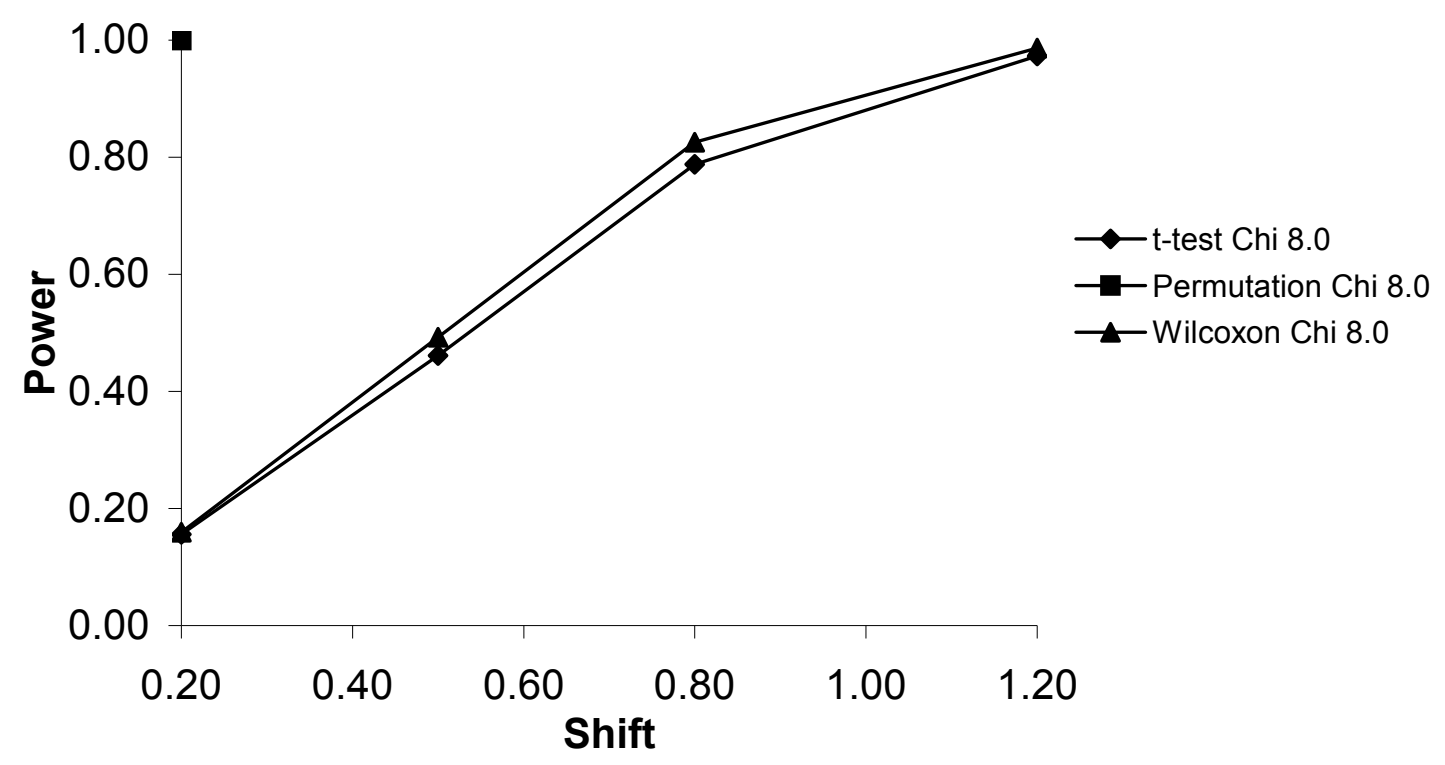

Figure 37: Shift vs. Power in the Chi-Square Distribution ( $d f=8)$ for Sample Size $n_{1}=n_{2}=20$

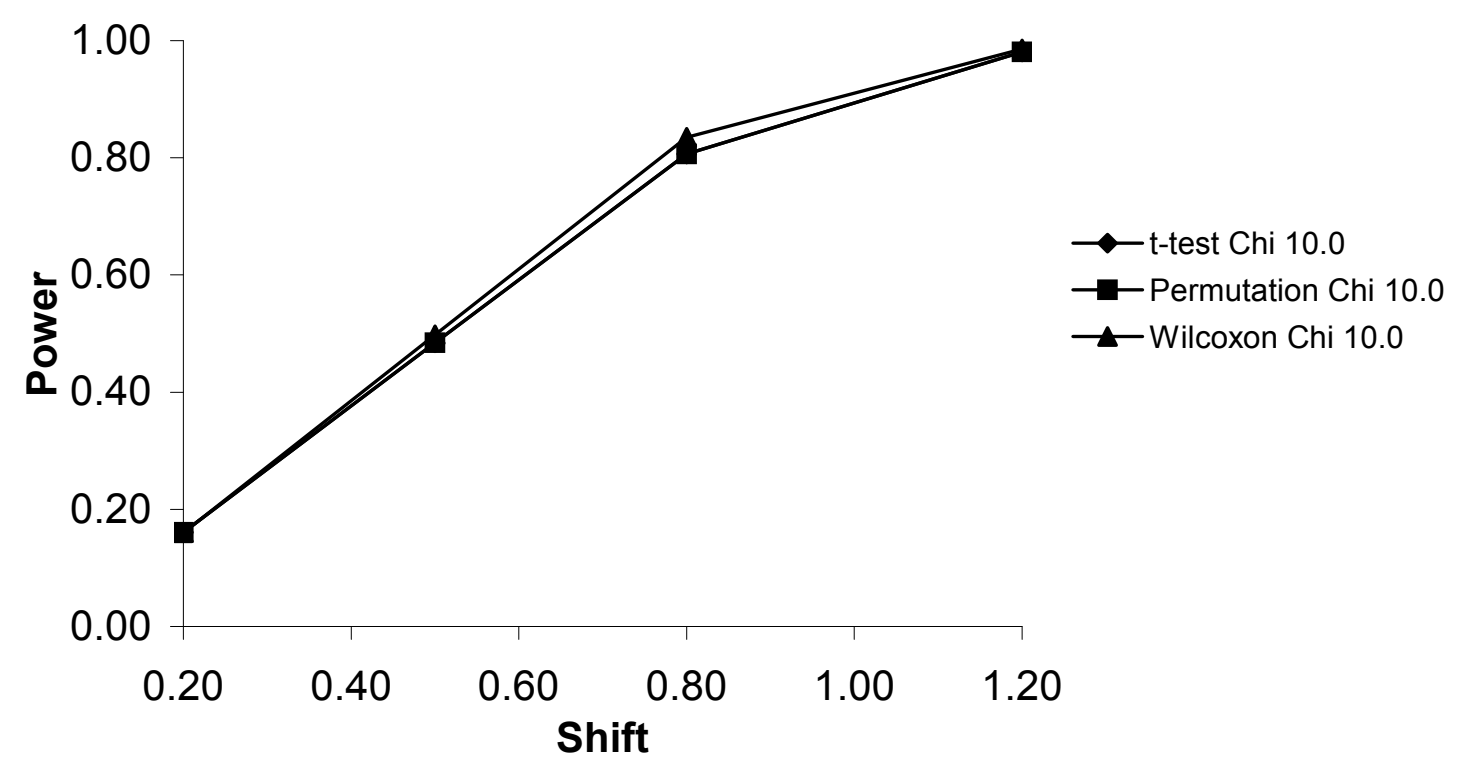

Figure 38: Shift vs. Power in the Chi-Square Distribution ( $d f=10)$ for Sample Size $n_{1}=n_{2}=20$ 


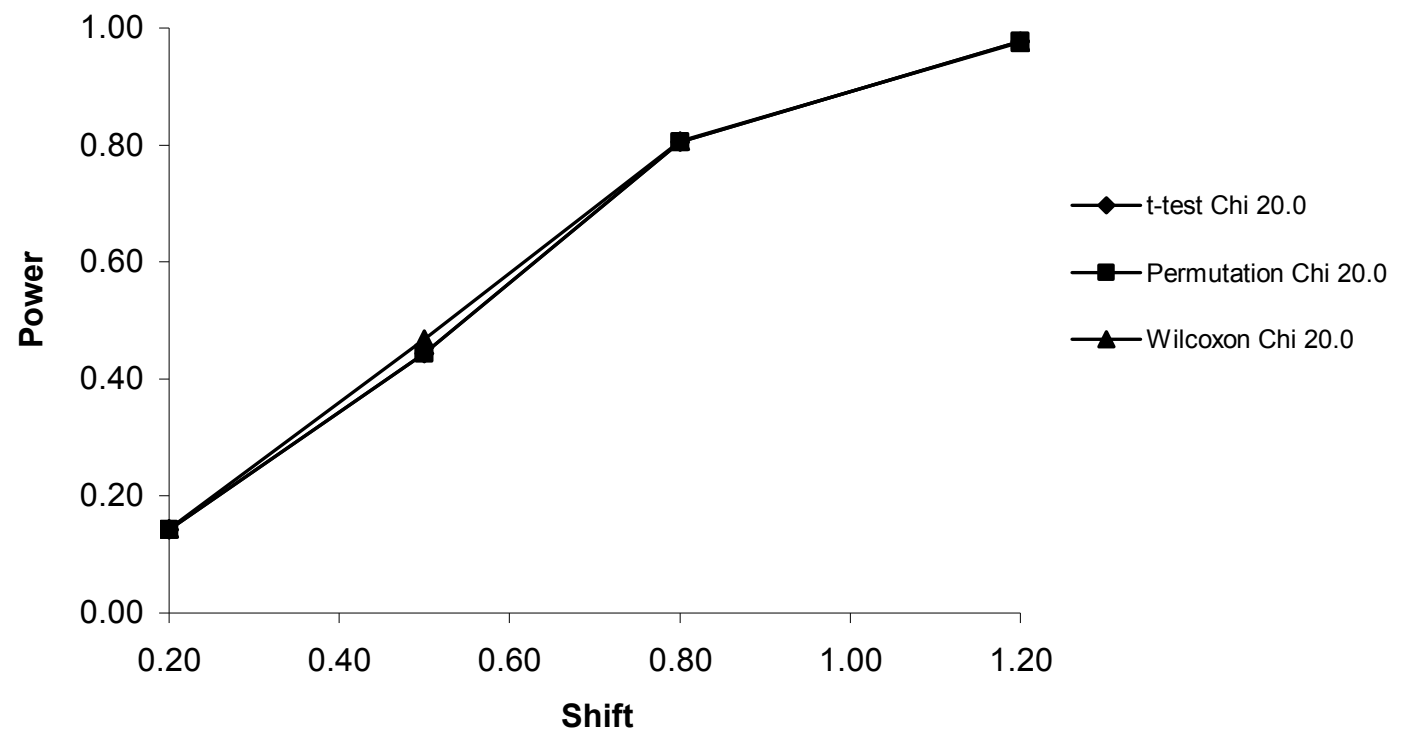

Figure 39: Shift vs. Power in the Chi-Square Distribution ( $d f=20)$ for Sample Size $n_{1}=n_{2}=20$

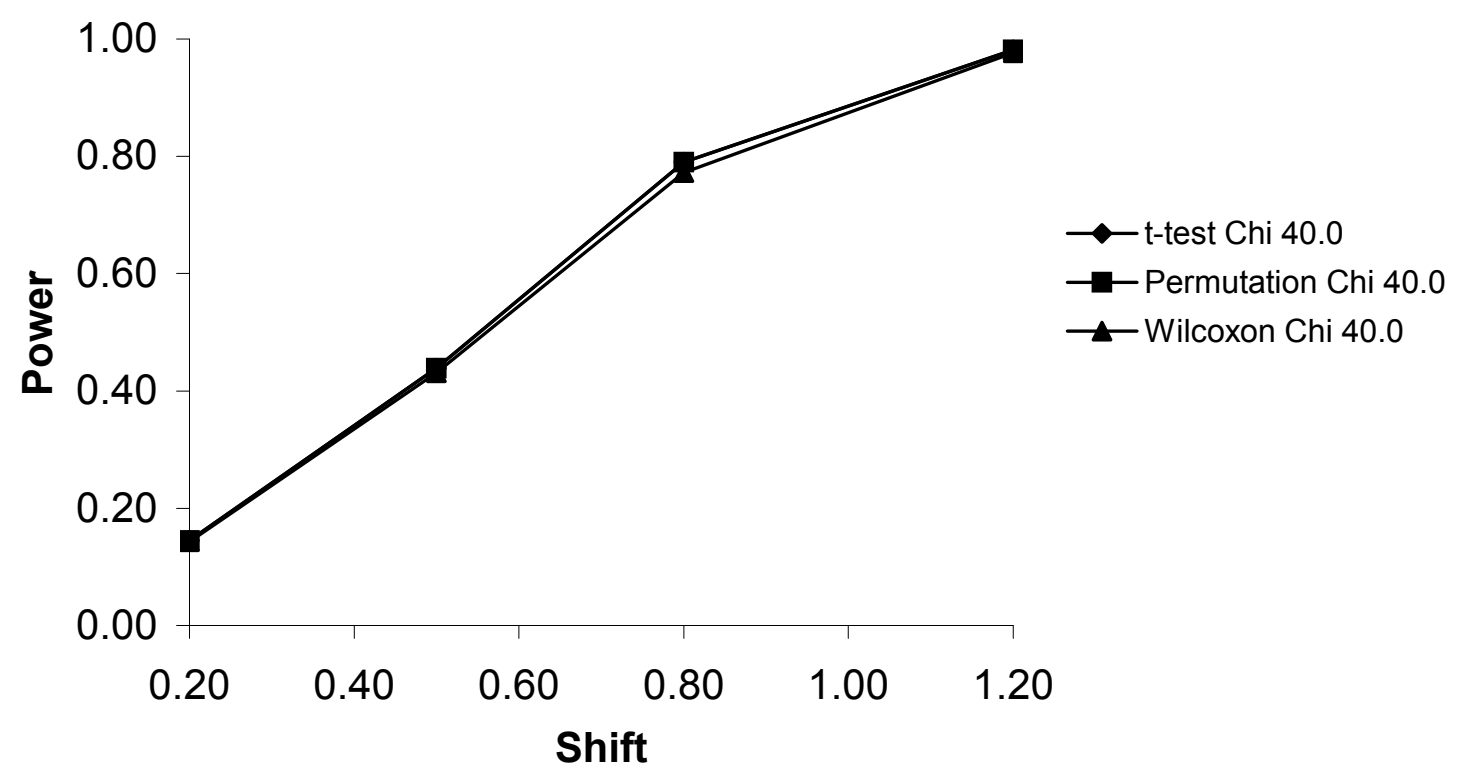

Figure 40: Shift vs. Power in the Chi-Square Distribution ( $d f=40)$ for Sample Size $n_{1}=n_{2}=20$ 